\title{
PURIFICACIÓN Y CARACTERIZACIÓN DE PROTEÍNAS BÁSICAS DE ESPERMATOZOIDES DE Argopecten purpuratus LAMARCK, 1819
}

\author{
Roberto Castellanos Cabrera ${ }^{\prime}$; Beatriz Lizárraga de Olarte $^{2}$ \\ Luz Doris Sánchez Pinedo ${ }^{2}$
}

\author{
RESUMEN
}

Los moluscos bivalvos presentan una gran variedad de proteínas específicas de diferentes pesos moleculares en las células espermáticas, con cantidades variables de los aminoácidos lisina, arginina, serina y alanina. Se han purificado y caracterizado cinco proteínas básicas en las células espermáticas del molusco bivalvo Argopecten purpuratus Lamarck 1819 que presentan características similares a las histonas somáticas de otras especies de invertebrados. El número de componentes de las proteínas y sus parámetros son variables entre las diferentes especies estudiadas; sin embargo, la composición química es muy similar en muchas de ellas. Se ha determinado la composición proteica nuclear especifica del espermatozoide del molusco bivalvo Argopecten purpuratus Lamarck 1819, que consiste en una mezcla heterogénea de histonas que poseen un set característico de proteínas de bajo peso molecular. Las proteínas nucleares específicas de A. purpuratus fueron purificadas por electroforesis preparativa, obteniéndose en forma bastante pura las fracciones denominadas $\mathrm{H1}, \mathrm{H} 2 \mathrm{a}-\mathrm{H} 2 \mathrm{~b}, \mathrm{H} 3, \mathrm{H} 4$ que presentan un alto contenido de lisina, arginina, serina y alanina; la fracción $H 3$ presenta cantidades equimolares de arginina, serina, prolina, valina y glicina.

\section{A B STRACT}

The bivalve mollusks present a great variety of specific proteins of different molecular weithin the spermatic cells, with variable quantities of the amino acids lysine, arginine, serine and alanine. They have become purified and characterized five basic proteins in the spermatic cells of the bivalue mollusk Argopecten purpuratus Lamarck 1819 that present characteristic similar to the somatic histones of other species of spineless. Although the number of components of the proteins and their parameters are variable among the different studied species, however the chemical composition is very similar in many of them. The composition specific nuclear protein of the sperm of the bivalve mollusk Argopecten purpuratus Lamarck, 1819 has been determined, that it consists on a heterogeneous mixture of histones that possess a characteristic set of proteins of under molecular weight. The proteins nuclear spermatic of A. purpuratus was purified by electrophoresis preparative, being obtained in quite pure form the denominated fractions $\mathrm{H1}, \mathrm{H} 2 \mathrm{a}-\mathrm{H} 2 \mathrm{~b}, \mathrm{H} 3, \mathrm{H} 4$ that present a high content in lysine, arginine, serine and alanine; the fraction $\mathrm{H} 3$ presents quantities equimolar of arginine, serine, proline, valine and glycine. 


\section{INTRODUCCIÓN.}

Las evidencias bioquímicas indican que en la cromatina de Argopecten purpuratus Lamarck existe el clásico arreglo nucleosomal, donde la partícula "core" está formada por dos moléculas de cada una de las principales histonas $\mathrm{H} 2 \mathrm{~A}, \mathrm{H} 2 \mathrm{~B}, \mathrm{H} 3$ y $\mathrm{H} 4$, con aproximadamente $140-150$ pares de bases de DNA. La histona $\mathrm{H} 1$ está localizada en la región del DNA internucleosomal, interactuando con la partícula "core" y con la molécula del DNA. La estructura altamente condensada de la cromatina espermática podría ser interpretada, en términos moleculares, por interacciones entre el DNA y las histonas espermioespecíficas. Dicha estructura puede esperarse que tenga fracciones estructurales comunes entre las diferentes especies. Los datos obtenidos indican que las histonas espermáticas tienen un comportamiento electroforético y propiedades de solubilidad virtualmente idénticas a las histonas de células somáticas; pero su composición de aminoácidos es diferente; en particular, la cantidad de residuos de arginina de la histona espermática $\mathrm{H} 1$ es mucho más alta. Las variaciones composicionales han sido establecidas entre histonas aisiadas de diferentes especies de moluscos bivalvos. Sin embargo, diferentes variantes de la misma fracción de histona han sido reportadas en esperma de la misma especie (Strickland et al, 1977). Si estas variaciones tienen un principio biológico, es presumiblemente desconocido. Como parte de un programa dirigido hacia la comprensión de las interacciones entre el DNA y las histonas específicas, que son responsables del estado condensado de la cromatina espermática y la represión del genoma espermático, se ha logrado la purificación y caracterización de las principales histonas del esperma maduro del molusco bivalvo Argopecten purpuratus Lamarck 1819 en el presente trabajo concluido en 1998.

\section{MATERIALES Y MÉTODOS}

El material biológico utilizado corresponde al esperma obtenido de especímenes maduros del molusco bivalvo Argopecten purpuratus Lamarck 1819 procedentes de la localidad de Pisco, ubicada al sur del Perú. Los núcleos espermáticos fueron obtenidos según los métodos que describen Subirana y col. (1973) y Chiva y col. (1992) con ligeras modificaciones realizadas por los autores. El esperma maduro obtenido por desove inducido y secuencial, fue primeramente filtrado a través de una malla nitex de $5 \mu \mathrm{m}$, permitiendo también la eliminación de los óvulos que siempre contaminan el esperma. El esperma filtrado fue centrifugado a 2,000 $\mathrm{xg}$ por 5 minutos. El sedimento 1 obtenido contiene una gran cantidad de espermatozoides maduros, los cuales pueden ser conservados en etanol al $90 \%$ y congelados a $-20^{\circ} \mathrm{C}$ Resuspendiendo el sedimento 1 con buffer $\mathrm{A}$ (sucrosa $0.25 \mathrm{M}_{1} \mathrm{MgCl}_{2} 10 \mathrm{mM}, \mathrm{CaCl}_{2} 3 \mathrm{mM}$, Tris- $\mathrm{HCl} 10 \mathrm{mM}$ $(\mathrm{pH} 7.0)$ y cloruro de benzamidina $10 \mathrm{mM}$ ) se procedió a homogenizar y centrifugar a 2,000 x g por 5 minutos. El sedimento 2 obtenido fue resuspendido en buffer $B$ (sucrosa $0.25 \mathrm{M}, \mathrm{MgCl}_{2} 10 \mathrm{mM}, \mathrm{CaCl}_{2} 3 \mathrm{mM}$, Tris- $\mathrm{HCl}$ $10 \mathrm{mM}$ (pH 7.0), Triton X-100 $0.1 \%$ helado y cloruro de benzamidina $10 \mathrm{mM}$ ). Se homogenizó suavemente con 5 golpes sobre hielo y se dejó en reposo por 10 minutos para permitir la acción del detergente sobre las membranas plasmáticas y colas de espermatozoides. Luego se procedió a centrifugar a $2,000 \times \mathrm{g}$ en una centrifuga refrigerada Sorvall con rotor SS-34 durante 5 minutos.

El sobrenadante fue eliminado y el sedimento 3 resuspendido en buffer $\mathrm{C}[\mathrm{Tris}-\mathrm{HCl} 10 \mathrm{mM}(\mathrm{pH} 7,0)$ y EDTA $20 \mathrm{mM}$ ], homogenizado con 5 golpes y centrifugado a $2,000 \times \mathrm{g}$ por 5 minutos. Al final se obtuvo el sedimento 4 constituido por núcleos espermáticos que fueron observados por microscopía a 450 aumentos. Este sedimento fue nuevamente resuspendido en buffer D [Tris- $\mathrm{HCl} 10 \mathrm{mM}(\mathrm{pH} \mathrm{7.0)]}$, homogenizado suavemente con cinco golpes, dividiéndolos en alícuotas y centrifugados a 2,000 xg por 5 minutos, eliminándose los sobrenadantes y conservando los sedimentos a $-20^{\circ} \mathrm{C}$. Una alícuota que contenia sedimento nuclear, después de su descongelación a $4{ }^{\circ} \mathrm{C}$, fue resuspendido con 4.5 volúmenes de $\mathrm{HCl} 0.4 \mathrm{~N}$ para extraer proteínas básicas totales (Subirana y col., 1973; Chiva y col., 1990), homogenizando con 20 golpes y centrifugando a 10,000 $x \mathrm{~g}$ por 20 minutos. El sobrenadante fue precipitado por adición de 6 volúmenes de acetona helada, dejando en reposo toda la noche a $-20^{\circ} \mathrm{C}$. Al día siguiente el sobrenadante precipitado fue centrifugado a 10,000 x g por 10 minutos, eliminando la acetona y lavando inmediatamente el precipitado con acetona acidificada helada, centrifugando a $10,000 \times \mathrm{g}$ por 15 minutos, resuspendiéndose el precipitado en $\mathrm{HCl} 0.01 \mathrm{~N}$ para serdializado, concentrado, liofilizado y conservado a $20^{\circ} \mathrm{C}$. La presencia de proteínas básicas específicas del molusco bivalvo Argopecten purpuratus fue posible evidenciarlas mediante electroforesis en gel de poliacrilamida-ácido acético-urea al 15\% (Panyim y Chalkley, 1969 modificado por Hurley, 1977). Se 
realizaron los cálculos para un volumen de $20 \mathrm{ml}$ (considerando que el espesor del gel fue de $0.75 \mathrm{~mm}$ ), donde se utilizaron: $10 \mathrm{ml}$ de solución de acrilamida al $29.8 \%$ y bis-acrilamida $0.2 \%, 2.5 \mathrm{ml}$ de ácido acético glacial al $43 \%, 7.5 \mathrm{~g}$ de urea, $17.5 \mathrm{mg}$ de thiourea y $112.5 \mu$ l de peróxido de hidrógeno al $30 \%$. La solución de poliacrilamida se filtró al vacío en Millipore de 0.22 $\mu \mathrm{my}$ desgasificó. El gel polimerizó en 30 a 40 minutos. Se realizó luego una electroforesis previa para eliminar el frente de iones que afectaría la electroforesis. Las muestras de proteínas liofilizadas en los procesos anteriores, luego de ser descongeladas bajo refrigeración, son disueltas en una concentración de 1 $\mathrm{mg} / \mathrm{ml}$ en buffer muestra. El buffer muestra estuvo constituido por urea $8 \mathrm{M}$, ácido acético glacial $5 \%$, 2mercaptoetanol $20 \mathrm{mM}$ y verde de metilo $1 \%$. Colocándose $10 \mu \mathrm{l}$ de cada muestra de proteína extraída en cada pocito de la placa de poliacrilamida. La corrida se realizó en una cámara electroforética de placa mediana por tres horas. La electroforesis se efectuó a un amperaje de $10 \mathrm{~mA}$ ó a un voltaje de 150 voltios conectando el ánodo en la cámara inferior y el cátodo en la cámara superior (teniendo presente que se tratan de proteínas básicas) hasta que el frente de corrida (verde de metilo) llegue al final de la placa. El buffer de electroforesis fue ácido acético al $5 \%$. Para la coloración simplemente se agrega Coomassie blue al $0.25 \%$. Para la decoloración de proteínas se utiliza de manera general metanol: agua bidestilada: ácido acético (5:5:1). Los geles se secan entre láminas de celofán o se aimacenan en bolsas plásticas selladas herméticamente. Las extracciones proteicas pueden ser separadas y purificadas por electroforesis preparativa en gel de poliacrilamida ácido acéticourea al $15 \%$ conteniendo un separador de mayor espesor $(1.5 \mathrm{~mm})$ y colocando mayor cantidad de muestra $(150 \mu \mathrm{l})$ para una mayor obtención de proteínas. El gel obtenido luego de coloreado con Coomassie Blue $0.1 \%$ en agua durante 30 segundos, es lavado en agua destilada y colocado en transiluminador para seccionar las bandas observadas con navaja. Cada banda proteica es desmenuzada con navaja en trocitos muy pequeños y colocados en tubos que contienen ácido acético al $5 \%$ en agitación constante durante 24 horas, separando después los geles desmenuzados de la solución ácida proteica mediante filtración. Cada uno de los filtrados fue dializado contra agua helada destilada, liofilizados y guardados a $-20^{\circ} \mathrm{C}$. Las proteínas liofilizadas son diluidas en buffer muestra y tratadas electroforéticamente en gel de poliacrilamida ácido acético-urea al $15 \%$ obteniéndose después el gel. Una vez que se han aislado las proteínas en estado purificado, se puede determinar su composición molar de aminoácidos. El método consta de 3 etapas: hidrólisis de la proteina, derivatización de los aminoácidos antes de ponerlos en la columna de análisis en cromatografía liquida de alta resolución (HPLC).

\section{RESULTADOS}

Se obtuvieron cantidades significativas de núcleos espermáticos a partir de esperma, siguiendo el procedimiento indicado en Material y Métodos. Se realizó el seguimiento microscópico a 450 aumentos para verificar la pureza de los núcleos. Los espermatozoides obtenidos por desove inducido o de manera directa de la gónada madura son biológicamente activos, observándose que poseen motilidad y capacidad de fertilizar oocitos extraídos por el mismo método. En la primera etapa de purificación fue necesario diluir el esperma, esto produjo un aumento inicial en la motilidad de los espermatozoides, lo cual facilitó la filtración en la malla de nitex de $5 \mu \mathrm{m}$. Luego la motilidad disminuyó en forma paulatina, aunque se observó que los espermatozoides mantenidos en agua de mar tratada con UV y pasada por Millipore de $0.22 \mu \mathrm{m}$ a $4^{\circ} \mathrm{C}$ a la que se agregó EDTA a una concentración de $0.1 \mathrm{mM}$, permanecen móviles después de 16 horas de realizado el desove. Las proteinas de Argopecten purpuratus extraídas con $\mathrm{HCl} 0.4 \mathrm{~N}$ poseen una movilidad electroforética semejante a la de las histonas totales de Tetrapygus niger "erizo de mar" (extraidas según el método de Giancotti y col.1983) con algunas variaciones en la banda correspondiente a la histona $\mathrm{H} 1$ y H3. La banda correspondiente a la histona $\mathrm{H} 4$ de $\mathrm{T}$. niger se encuentra en igual posición que la correspondiente a Argopecten purpuratus; puede asegurarse que corresponde a la histona $\mathrm{H} 4$ en la especie en estudio por la migración electroforética idéntica. La que difiere es la que interpretamos como la histona $\mathrm{H} 1$, que se muestra diferente en su densidad. Como puede desprenderse de los estudios realizados, las proteínas básicas nucleares de Argopecten purpuratus se caracterizan por presentar un cierto grado de heterogeneidad, tanto de las fracciones solubles en ácido acético y que son aquéllas tipo histonas, como de las proteínas solubles en $\mathrm{HCl} 0.4 \mathrm{~N}$ y que se les ha denominado proteínas parecidas a protaminas por su contenido especial de aminoácidos, que presentan un 
porcentaje mayoritario de los aminoácidos lisina, arginina, serina y alanina. También podemos afirmar que son protaminas de alto peso molecular, característico de los moluscos bivalvos (Ausió, 1986). Las relaciones que presentan las proteínas básicas específicas de espermatozoides de la especie Argopecten purpuratus podemos observarlas en la Figura 1.

Purificadas las proteínas, se determinó la composición de aminoácidos por cromatografía líquida de alta resolución. Se sabe que en espermatozoides y en gónadas de varias especies de moluscos existen proteínas parecidas a las histonas somáticas que son específicas de espermatozoides (Subirana y col., 1973; Colom y Subirana, 1979, 1981) o las gónadas y que pueden coexistir con proteínas parecidas a protaminas. El sistema utilizado consiste en electroforesis en gel de poliacrilamida al $15 \%$, con el que se separan las 5 bandas correspondientes a las histonas: $\mathrm{H} 1, \mathrm{H} 2 \mathrm{~A}$, $\mathrm{H} 2 \mathrm{~B}, \mathrm{H} 3$ y H4, a veces aparecen productos de degradación parcial de alguna de ellas. En la Figura 1 , se observan las bandas de proteína histónica extraídas del núcleo espermático $(\mathrm{H} 1, \mathrm{H} 2 \mathrm{~A}, \mathrm{H} 2 \mathrm{~B}, \mathrm{H} 3$ y H4). La presencia de la histona $\mathrm{H} 1$ es notoria como una doble banda de menor velocidad de migración.

Figura 1. Proteinas básicas de Argopecten purpuratus separadas por electroforesis en gel de poliacrilamida.

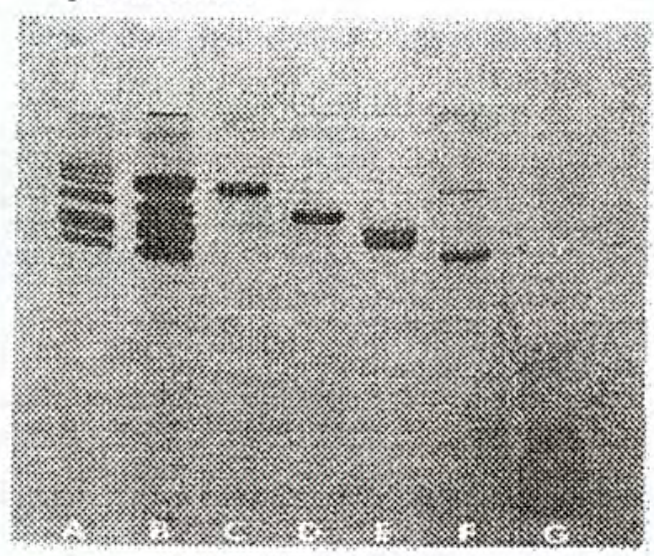

A. Proteinas totales de Tetrapygus niger

B. Proteínas totales de Argopecten purpuratus

C. Histona $\mathrm{H} 1$ de Argopecten purpuratus

D. Histona $\mathrm{H} 3$ de Argopecten purpuratus

E. Histona $\mathrm{H} 2 \mathrm{~A}-\mathrm{H} 2 \mathrm{~B}$ de Argopecten purpuratus

F. Histona $\mathrm{H} 4$ de Argopecten purpuratus

G. Protamina Salmina
Tabla 1. Composición de aminoácidos de proteinas básicas especificas de Argopecten purpuratus Lamarck 1819 (Moles \%)

\begin{tabular}{|l|r|c|r|r|}
\hline \multicolumn{1}{|c|}{ AMINOÁCIDO } & H1 & H2A-H2B & H3 & H4 \\
\hline Lisina & 27.4 & 27.2 & 16.7 & 12.0 \\
\hline Arginina & 11.9 & 8.1 & 10.3 & 11.9 \\
\hline Histidina & 0.2 & 0.7 & 2.5 & 2.2 \\
\hline Aspartato & 1.7 & 2.8 & 0.0 & 5.2 \\
\hline Treonin T Treonina & 0.9 & 1.2 & 3.0 & 1.7 \\
\hline Serina & 16.8 & 8.4 & 6.6 & 7.9 \\
\hline Glutamato & 1.3 & 2.7 & 9.1 & 7.2 \\
\hline Prolina & 11.3 & 8.9 & 0.2 & 4.1 \\
\hline Glicina & 5.4 & 7.8 & 9.6 & 15.1 \\
\hline Alanina & 17.2 & 16.0 & 16.7 & 8.6 \\
\hline Cisteina & 1.5 & 0.3 & 0.0 & 0.0 \\
\hline Valina & 5.9 & 8.7 & 7.2 & 1.9 \\
\hline Metionina & 1.1 & 1.8 & 1.4 & 0.7 \\
\hline Isoleucina & 1.4 & 2.5 & 6.0 & 3.8 \\
\hline Leucina & 2.2 & 3.5 & 8.7 & 5.6 \\
\hline Tirosina & 0.9 & 1.2 & 3.0 & 1.7 \\
\hline Fenilalanin & 1.0 & 1.4 & 2.0 & 1.7 \\
\hline Lis/Arg & 2.3 & 3.4 & 1.6 & 1.0 \\
\hline Bas./Acido & 13.2 & 6.5 & 3.2 & 2.1 \\
\hline
\end{tabular}

Básicos $/$ Ácidos $=$ Lys + His + Arg $/$ Asp + Glu

\section{DISCUSIÓN}

En términos generales, la organización in vivo de la cromatina espermática, que involucra la interacción entre los componentes proteicos parecidos a protaminas y el DNA, permanece completamente desconocida y desafía muchos esfuerzos para averiguarlo (Ausió, 1980; Ausió y Subirana, 1983; Zalensky y col., 1982; Avramova y col, 1984). Experimentos de reconstitución llevados a cabo in vitro (Ausió y Suau, 1983) sugieren una similitud estrecha entre tales tipos de nucleoproteínas y la organización típica nucleoprotamina. El estudio de las proteinas básicas específicas del núcleo de células espermáticas de la especie analizada, nos ha permitido mostrar las semejanzas entre los géneros Argopecten y Tetrapygus. En la especie Argopecten purpuratus, de la familia Pectinidae, existen componentes específicos a los que hemos 
denominado $\mathrm{H}_{1}, \mathrm{H}_{2 \mathrm{~A}}, \mathrm{H}_{2 \mathrm{~B}}, \mathrm{H}_{3}, \mathrm{y} \mathrm{H}_{4}$. El hecho de que estos bivalvos presenten ambos tipos proteicos (histonas y protaminas) nos plantea un problema en cuanto al tipo de interacción de estas variantes proteicas con el DNA; aún no se sabe qué tipo de interacción habria, aunque se han realizado algunos estudios en otros bivalvos; sin embargo, no existe una explicación de la función que estarían cumpliendo estas proteínas. El modo de interacción de estas proteínas con el DNA pudiera ser nucleosomal, tipo ligando protamina-DNA u otro tipo de interacción, en la que se observe probablemente las dos interacciones antes dichas. La organización in vivo de la cromatina del espermatozoide, que involucra a la interacción entre los componentes proteicos parecidos a protaminas y el DNA, aún está en un plano especulativo, a pesar de los estudios realizados por Ausió (1980), Ausió y Subirana (1982), Zalensky y col. (1982). Es de notar también que el análisis electroforético y de la composición realizado en este trabajo puede servirnos de mucha ayuda en los análisis de taxonomia, pues es un hecho que existen diferencias inter e intra específicas y estos análisis introducirían un parámetro de comparación más claro, observando las diferencias de proteinas básicas nucleares específicas del espermatozoide, estudiando las diferencias en subespecies y observando algún nivel de variación local o geográfica dentro de la misma especie. De acuerdo con diversos autores (que resume Kasinsky, 1989) existiría una relación importante en la biología de la reproducción, que estamos corroborando en estos estudios. Que los animales con fertilización externa, como los moluscos pelecípodos de este trabajo, presentan proteinas parecidas a protaminas con un alto contenido de lisina, arginina, serina y alanina, $y$ son proteinas de alto peso molecular en comparación con las protaminas clásicas somáticas que tienen pesos moleculares que fluctúan entre 4,000 y 8,000 . El estudio de las proteinas espermioespecificas del núcleo de células espermáticas de la especie analizada ha permitido mostrar las diferencias que existen entre las familias Pectenidae y otros pelecípodos estudiados.

En la familia Pectinidae, mayormente las proteinas son histonas, según refiere Ausió(1986) en sus estudios realizados electroforéticamente en geles de urea $6 \mathrm{M}$ y en el cual clasifica de acuerdo a su composición en proteínas parecidas a protaminas.
Experimentos de reconstrucción in vitro realizados por Ausió y Suau (1983) sugieren una cercania entre las diferentes clases de complejos nucleoproteicos y la organización núcleo-protamínica típica.

Tabla 2. Clasificación de moluscos bivalvos de acuerdo con su composición de protaminas parecidas, según Ausió, J. (1986).

\begin{tabular}{|l|c|l|}
\hline \multicolumn{1}{|c|}{ FAMILIAS } & GRUPO & \multicolumn{1}{c|}{ PROTAMINAS } \\
\hline Pectenidae & O & (histonas) \\
\hline Veneridae & I & PL-I \\
\hline Cardidae & II & PL-I, PL-II \\
\hline Tellinidae & III & PL-I, PL-II, PL-III \\
\hline Mytilidae & N & PL-II, PL-III, PL-IV \\
\hline
\end{tabular}

La Tabla 3 estaría siendo completada si consideramos a la especie Argopecten purpuratus Lamarck 1819. Es de notar también que el análisis electroforético y la composición realizados en este trabajo pueden servirnos de mucha ayuda en los análisis de taxonomia, pues es un hecho que existen diferencias inter e intraespecificas y estos análisis introducirian un parámetro de comparación más claro, observando las diferencias de proteínas básicas nucleares especificas del espermatozoide estudiando las diferencias en subespecies y observando algún nivel de variación local o geográfica dentro de la misma especie.

Tabla 3. Ordenes, familias, géneros y especies estudiadas en el presente trabajo clasificados de acuerdo con Coan y Carlton (1975) y la Tabla 2.

\begin{tabular}{|c|c|c|}
\hline $\begin{array}{l}\text { ORDEN, } \\
\text { FAMILIA }\end{array}$ & ESPECIE & $\begin{array}{c}\text { GRUPO } \\
\text { Protamina }\end{array}$ \\
\hline $\begin{array}{l}\text { Veneroidea } \\
\text { Veneridae } \\
\text { Mactridae } \\
\text { Hiatellidae }\end{array}$ & $\begin{array}{l}\text { Protothaca staminea } \\
\text { Tapes japonica } \\
\text { Saxidomos giganteus } \\
\text { Spisula solidissima } \\
\text { Tresus capax } \\
\text { Panope generosa }\end{array}$ & $\begin{array}{l}1 \\
1 \\
1 \\
1 \\
1 \\
1\end{array}$ \\
\hline $\begin{array}{l}\text { Cardidae } \\
\text { Myodea } \\
\text { Myidae } \\
\end{array}$ & $\begin{array}{l}\text { Clinocardium muttalli } \\
\text { Mya a renaria }\end{array}$ & II \\
\hline $\begin{array}{l}\text { Solenidae } \\
\text { Tellinidae }\end{array}$ & $\begin{array}{l}\text { Ensis minor } \\
\text { Macona Sp }\end{array}$ & $\begin{array}{l}\text { III } \\
\text { III }\end{array}$ \\
\hline $\begin{array}{l}\text { Mytiloidea } \\
\text { Mytilidae }\end{array}$ & $\begin{array}{l}\text { Mytilus californianus } \\
\text { Mytilus edulis }\end{array}$ & $\begin{array}{l}\mathrm{IN} \\
\mathrm{IV}\end{array}$ \\
\hline $\begin{array}{l}\text { Pteroidea } \\
\text { Pectinidae } \\
\text { Ostreidae } \\
\end{array}$ & $\begin{array}{l}\text { Aequipecten irradians } \\
\text { Argopecten purpuratus } \\
\text { Crassostrea gigas }\end{array}$ & $\begin{array}{l}0 \\
0 \\
0\end{array}$ \\
\hline
\end{tabular}




\section{CONCLUSIONES}

1. Se han purificado y caracterizado cinco proteínas básicas espermioespecíficas del molusco bivalvo Argopecten purpuratus Lamarck 1819:

2. La proteína parecida a $\mathrm{H} 1$ es rica en lisina $(27.4 \%)$, alanina $(17.2 \%)$, serina $(16.8 \%)$, arginina $(11.9 \%)$ y prolina $(11.3 \%)$.

3. La proteína parecida a $\mathrm{H} 3$ es rica en lisina (27.2\%), alanina $(16.0 \%)$, prolina $(8.9 \%)$, valina $(8.7 \%)$, serina $(8.4 \%)$.

4. Las proteínas parecidas a $\mathrm{H} 2 \mathrm{a}-\mathrm{H} 2 \mathrm{~b}$ son ricas en lisina $(16.7 \%)$, alanina $(16.7 \%)$, arginina (10.3\%), glicina $(9.6 \%)$ y valina $(7.2 \%)$.

\section{REFERENCIAS BIBLIOGRÁFICAS}

AUSıÓ, J.: "Caracterización de las protaminas de los moluscos Bivalvos: Mytilus edulis y Spisula solidissima $y$ estudio de sus interrelaciones con el ADN". Tesis. Universidad de Barcelona. Facultad de Ciencias Biológicas, 1980.

AUSIÓ, J. \& SUBIRANA, J.A.: "A high molecular weight nuclear basic protein from the bivalve mollusc Spisula solidissima", J. Biol. Chem., 257, 2802-2805, 1982.

AUSIÓ, J.: "Structural variability and compositional homology of the protamine like components of the sperm from the bivalve molluscs", Comp. Biochem. Physiol., 85B, 439-449, 1986.

AUSIÓ, J.: "Presence of a highly specific histone $H 1$ like protein in the chromatin of the sperm of the bivalve mollusks", Mol. Cell. Biochem., 115, 163-72, 1992.

BANDIERA, A.; PATEL,U.A.; MANFIOLETTI, G.; RUSTIGHI, A.; GIANCOTTI, V.\& CRANE-ROBINSON, C.: "A precursor product relationship in molluscan sperm proteins from Ensis minor", Eur. J. Biochem., 233, 744-9, 1995.

CHIVA, M.; ROSENBERG, E.; KASINSKY H.E.: "Nuclear basic proteins in mature testis of the ascidian tunicate Styela montereyensis". J. Exp.Zool. 253: 7-19, 1990.

CHIVA, M.; DABAN, M.; ROSENBERG, E.; KASINSKY, H.E.: "Protamines in polyplacophors and gastropods as a model for evolutionary changes in molluscan sperm basic proteins". In B. Bacceti (ed): "Comparative Spermatology 20 Years After", Vol. 75. Siena, Italy: Raven Press, pp 27-30, 1992.

COLOM, J. \& SUBIRANA, J.A.: "Presence of H2b histone in spermatozoa from marine gastropods". Exp.Cell.Res. 131, 462-465, 1981.
5. Las proteinas parecidas a $\mathrm{H} 4$ son ricas en glicina $(15.1 \%)$, lisina $(12 \%)$, arginina $(11.9 \%)$, alanina $(8.6 \%)$ y serina $(7.9 \%)$.

6. Se demuestra en núcleos espermáticos la coexistencia de proteinas sólo de tipo histonas, sin proteinas tipo protaminas.

DESILETS, J.; GICQUAUD, D. \& DUBE, F.: "An ultrastrutural analysis of early fertilization events in the giant scallop, Placopecten magellanicus (Mollusca, Pelecypoda)", Inverte- brate Reproduction and Develop-ment, 27, 115-129, 1995.

GIANCOTTI, V.; RUSSO, E.: GASPARINI, M.; SERRANO, D. DEL PIERO; D. THORNE, A.W.; CARY, P.D. \& CRANEROBINSON, C. Eur. J. Biochem. 136, 509-516. 1983.

GUEVARA, L.; MELGAR, E. \& LIZARRAGA, B.:"Purification of sperm chromatin and nucleosome core particles from the sea urchin Tetrapygus niger". Acta. Cient. Venezolana 34:3943, 1983.

HURLEY, C. K.: "Electrrophoresis of Histones: A Modified Panyim and Chalkley System for Slab Gels". Analytical Biochemistry 80, 624-626, 1977.

KASINSKY, H.E.: "Specificity and distributions of sperm basic proteins". In: "Histones and others Basic Nuclear Proteins". L. Hnilica, G. Stein, and J. Stein, Eds. CRC Press, Boca Raton, F.L., 1989.

PANYIM, S. \& CALKLEY, R.: "High Resolution Acrylamide Gel Electrophoresis of Histones". Archives of Biochemistry and Biophysics 130, 337-346, 1969

SANCHEZ, L.D.: "Estudio de las proteinas básicas especificas del núcleo de espermatozoides de Semele solida Gray, 1828, Mesodesma donacium Lamarck y Thais stramonita chocolata Duclos", 1832. Tesis Doctoral. Universidad Nacional Mayor de San Marcos, 1990. 